ORIGINAL RESEARCH

\title{
Victims' Response to Snakebite and Socio-epidemiological Factors of 1018 Snakebites in a Tertiary Care Hospital in Sri Lanka
}

\author{
Abeysinghe M. Kularatne, MD, MRCP, FRCP, FCCP; Anjana Silva, MBBS, MPhil; Kalana Maduwage, MBBS, \\ MPhil; Ishani Ratnayake, MBBS; Chmara Walathara, MBBS; Chanka Ratnayake, MBBS; Suresh Mendis, MBBS, \\ MD, MRCP; Ranjith Parangama, MBBS, MD \\ From the Department of Medicine, Faculty of Medicine, University of Peradeniya, Peradeniya, Sri Lanka (Drs Kularatne and C. Ratnayake); \\ Department of Parasitology, Faculty of Medicine and Allied Sciences, Rajarata University of Sri Lanka, Saliyapura, Sri Lanka (Dr Silva); School \\ of Medicine and Public Health, Faculty of Health, University of Newcastle, New South Wales, Australia, and Department of Biochemistry, Faculty \\ of Medicine, University of Peradeniya, Peradeniya, Sri Lanka (Dr Maduwage); Anuradhapura, Sri Lanka (Dr I. Ratnayake); and Anuradhapura \\ Teaching Hospital, Anuradhapura, Sri Lanka (Drs Walathara, Mendis, and Parangama).
}

Background.-Although snake bite remains a major health problem in Sri Lanka, there is a dearth of baseline information that would be useful in education about and prevention of snakebite.

Objectives.-The purpose of this study was to describe the socio-demographic characteristics, behavioral responses, treatment seeking, and prehospital interventions of snakebite victims in an area with high snakebite burden.

Methods. - This prospective study was based on a cohort of snakebite victims presented to the Anuradhapura Teaching Hospital over a 1-year period from January 2010.

Results.-Of the total of 1018 snakebite admissions, 69\% were male and 65.8\% were aged 21 to 50 years. Most of the victims were farmers (40\%). The offending snakes were seen by 549 victims (54\%); of these, only 46\% (255) presented with a dead snake specimen. Only 38 of 1018 (4\%) had first sought some form of indigenous treatment such as locally applied medications, herbal decoctions, nasal insufflations ("Nasna"), or applying snake stone over the bitten site. Some form of first aid had been adopted by 681 victims (67\%), of whom all had washed the bitten site, and 18 victims (2\%) and 4 $(0.4 \%)$ had applied a dressing or incised the bitten site, respectively. A tourniquet had been applied by 353 victims (35\%) for mean duration of 26 minutes (range, 5 to 120 minutes). None of the patients had immobilized the bitten limb by splinting. Oral medications had been used for pain relief in 74 cases (7\%), paracetamol by all.

Conclusions. - A proportion of patients still seek native remedies and use inappropriate first aid after snakebite in Sri Lanka.

Key words: snakebite, sociodemography, prevention, first aid, treatment seeking

\section{Introduction}

Snakebite remains a major, yet neglected health problem in the tropical world, with the most affected being developing countries in South Asia, Southeast Asia, Sub-Saharan Africa, and Latin America. ${ }^{1}$ In confronting the global burden of snakebite, poor reporting, especially in the most affected regions, is considered a major

Corresponding author: Anjana Silva, MBBS, MPhil, Rajarata University of Sri Lanka, Department of Parasitology, Faculty of Medicine and Allied Sciences, Saliyapura, Anuradhapura, Sri Lanka (e-mail: nkanjanasilva@gmail.com). setback. $^{2}$ Understanding of the socio-epidemiological determinants of snakebite unique to different populations is pivotal in implementing preventive, educational, and therapeutic approaches in these regions, especially at the community level.

Based on available hospital statistics, 37,000 snake bites occur annually in Sri Lanka, of which the highest number of snakebites are recorded from the dry zone., Almost all the venomous snakebites in Sri Lanka are from Russell's viper (Daboia russelli), common Krait (Bungarus caeruleus), cobra (Naja naja), saw-scaled viper (Echis carinatus), and hump-nosed pit vipers 
(Hypnale hypnale, $H$ nepa, and $H$ zara). ${ }^{4-6}$ Although clinical profiles of envenoming by these snakes have been somewhat well documented, ${ }^{6-10}$ responses of the Sri Lankan victims to snakebite is less discussed in the literature. Improved understanding of victims' responses may improve the practicality of community-based snakebite prevention programs.

Based on a cohort of snakebite victims admitted over a 1-year period, we describe here some of the sociodemographics, behavioral responses, treatment, and prehospital interventions of snakebite victims presenting to a tertiary care facility in the Anuradhapura District of Sri Lanka.

\section{Methods}

The study was conducted from January to December 2010 in the emergency treatment unit of the Teaching Hospital Anuradhapura (THA), which is the largest tertiary care hospital in the North-Central Province and also the dry zone of Sri Lanka. All patients admitted with a history of snakebite were enrolled for the study, and data were prospectively collected from the patients through investigator-completed questionnaires. The information from patients with altered consciousness and children was acquired from the bystanders and relatives. Maximum effort was made to minimize the apparent reporting bias associated with obtaining information from a third party, by taking information only from those who accompanied the patient after the snakebite.

All the snake specimens brought with patients were collected and transported to the University of Peradeniya and were identified using identification keys in De Silva ${ }^{11}$ and Maduwage et al. ${ }^{12}$

Ethical clearance for this study was obtained from the Ethics Review Committee, Faculty of Medicine, University of Peradeniya.

\section{Results \\ DEMOGRAPHIC AND EPIDEMIOLOGIC CHARACTERISTICS}

A total of 1018 snake bite victims were admitted to the emergency treatment unit of THA during the study period. The Table and Figure 1 describe the demographic characteristics of study participants and the epidemiologic characteristics of snakebites.

\section{OFFENDING SNAKE}

Of the participants, 549 (54\%) had seen the offending snake after the bite. Of these, $266(48.5 \%)$ had killed the snake, and 255 (46.4\%) had brought the snake specimen to the local hospital or to THA. The 206 snake specimens brought to THA included $75 H$ hypnale $(36.4 \%)$, $47 \mathrm{D}$ russelli $(22.8 \%), 22 \mathrm{~B}$ caeruleus $(10.6 \%)$, and 7 Naja naja (3.4\%). In addition, these specimens also included 1 specimen each of Trimerusurus trigonocephalus and $E$ carinatus, and also 53 specimens of nonvenomous snakes $(25.6 \%)$. Of the victims who brought the snake to the THA, $76.8 \%$ had attempted to identify the snake, and $65.8 \%$ of these were accurate.

\section{PREHOSPITAL FIRST AID INTERVENTIONS}

Of the victims, $841(82.6 \%)$ had practiced at least a single prehospital remedy or intervention, which are described in the Table. Washing the bite site and applying a tourniquet were the most practiced interventions, and the median time spent for these interventions was 5 min (range 2-15 minutes) and 26 minutes (range 5-120 minutes, $\mathrm{SD} \pm 13.33$ minutes), respectively. Of the victims who had washed the bite site, $436(64.0 \%)$ had used soap and $84(12.3 \%)$ had used lime juice for washing. Among the authenticated viperine bites, $44.1 \%$ of the victims had applied a tourniquet to a limb. Among the snakebite victims who had applied substances over the bite site, 14 (50\%) had used herbal leaves and $9(32 \%)$ had used oil. Paracetamol was taken by $74(7.2 \%)$ victims before admission.

\section{TREATMENT-SEEKING BEHAVIOR}

The vast majority of the snakebite victims had sought Western treatments as the first option, and only 38 victims $(3.7 \%)$ had sought indigenous treatments before admission to hospital, for which they had spent a mean time of 54 minutes (range 10-360 minutes). "Nasna" (cleansing of the nose or insufflations) had been performed for 2 snakebite victims. Herbal decoctions taken by the victims included liquid forms such as Arista and Karapincha Kanji (Curry leaves, Murraya koenigii) and solid or semisolid forms such as Kalka. Arista is a form of herbal wine, prepared by fermenting herbs in sugary liquid preparation. The alcohol produced during the fermentation enhances extraction of the active components from the herbs. Kalka is prepared by adding jaggery, sugar, or sugar candy to the original herbal preparations and boiling. Both the Arista and Kalka are prepared using a range of herbal ingredients, and the compositions of these vary greatly from one practitioner to another.

\section{CLINICAL OUTCOME}

In the hospital setting, antivenom was administered for 397 patients and mechanical ventilation was required for 
Table. Socio-demographic factors and the first aid measures adopted by the 1018 snakebite patients admitted to Teaching Hospital Anuradhapura during the 1-year study period

\begin{tabular}{|c|c|}
\hline $\begin{array}{l}\text { Socio-demographics and } \\
\text { first aid measures }\end{array}$ & Number of cases (\%) \\
\hline Male & 705 (69) \\
\hline Female & $313(31)$ \\
\hline \multicolumn{2}{|l|}{ Highest education } \\
\hline Less than school grade 5 & $48(5)$ \\
\hline School grade 5 to 11 & $866(85)$ \\
\hline Up to GCE (advanced level) & $51(5)$ \\
\hline Tertiary education & $4(0.4)$ \\
\hline Unknown & $49(5)$ \\
\hline \multicolumn{2}{|l|}{ Occupation } \\
\hline Farmer & $407(40)$ \\
\hline Housewife & $148(14)$ \\
\hline Schooling & $69(7)$ \\
\hline Security personnel & $28(3)$ \\
\hline Businessman & $26(2.5)$ \\
\hline Teacher & $16(2)$ \\
\hline Mason & $8(1)$ \\
\hline Laborer & $5(0.5)$ \\
\hline Clerk & $5(0.5)$ \\
\hline Driver & $5(0.5)$ \\
\hline Other & $20(2)$ \\
\hline Unknown & $281(28)$ \\
\hline \multicolumn{2}{|l|}{ Time of bite } \\
\hline 0600-1159 hours & $223(22)$ \\
\hline $1200-1759$ hours & $285(28)$ \\
\hline 1800-0559 hours & $504(49)$ \\
\hline No data & $6(0.6)$ \\
\hline \multicolumn{2}{|l|}{ Site of bite } \\
\hline Below ankle & $812(80)$ \\
\hline Leg & $49(5)$ \\
\hline Hand & $114(11)$ \\
\hline Upper limb & $24(2)$ \\
\hline Head & $4(0.4)$ \\
\hline Body & $10(1)$ \\
\hline Unidentified & $5(0.5)$ \\
\hline \multicolumn{2}{|l|}{ First aid measures } \\
\hline Washing site of bite & $681(67)$ \\
\hline Incising site of bite & $4(0.4)$ \\
\hline Application of tourniquet & $353(35)$ \\
\hline Oral suction of site of bite & $1(0.1)$ \\
\hline Dressing applied over site of bite & $18(2)$ \\
\hline Snake stone kept over site of bite & $1(0.1)$ \\
\hline \multicolumn{2}{|l|}{ bite } \\
\hline Ingestion of herbal decoctions & $7(1)$ \\
\hline Splinting of bitten limb & $0(0)$ \\
\hline Elevation of bitten limb & $5(0.5)$ \\
\hline Removal of bangles and rings on & $2(0.2)$ \\
\hline \multicolumn{2}{|l|}{ bitten limb } \\
\hline Oral medications & $74(7)$ \\
\hline
\end{tabular}

GCE, Government Certificate Examination.

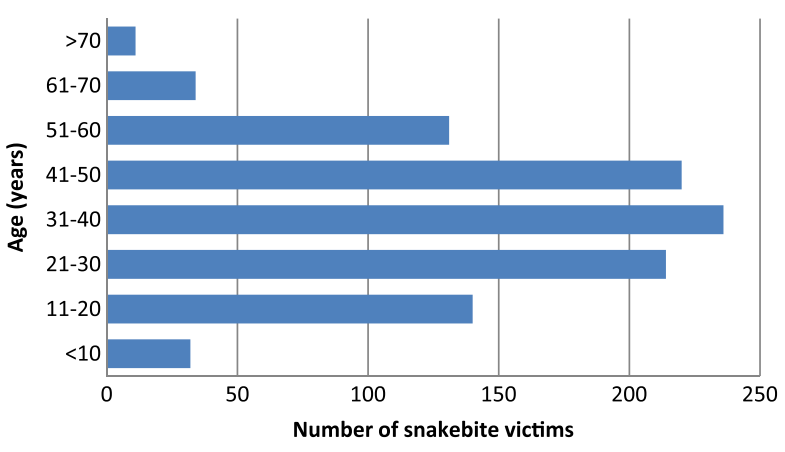

Figure 1. Age distribution of the 1018 snake bite victims studied.

25 patients $(2.46 \%)$. Nine $(0.88 \%)$ of the snakebite victims died of complications of envenoming.

\section{Discussion}

The demographic characteristics of the snakebite victims in the present study suggests that the features of those most commonly exposed to snakebite in Anuradhapura include being middle aged, male, and having relatively limited formal education. This picture is generally similar to the socio-demographic profile of snakebite victims across many affected regions throughout the tropics. ${ }^{13,14}$ However, some of the victims also have represented a range of age groups and other occupations. Furthermore, the distribution of the bites evenly during day time and night suggest the widespread importance of snakebite to the Sri Lankan society, rather than merely to the farming community.

The vast majority $(80 \%)$ of the victims had snakebites below the ankle, which emphasizes the importance of wearing protective footwear while engaging with high exposure activities like farming and walking on footpaths at dusk. Wearing protective footwear had effectively reduced the snakebite among risk groups in Myanmar. ${ }^{15}$ However, at present, health promotional programs on snakebite prevention in Sri Lanka remain largely overlooked. Therefore, these statistics support the promotion of using protective footwear by those in highrisk groups.

This study suggests that a low percentage of victims bring the offending snake to the hospitals. This finding emphasizes the value of alternative methods like the syndromic approach with possible immunodiagnostic techniques for confirmation of the offending snake species whenever possible. In addition, one third of the offending snake specimens are inaccurately identified by the victims. Therefore, this study provides additional evidence for the unreliability of patients' identification of the offending snake to assist routine snakebite management and in clinical snakebite research. The availability 
of the offending snake for identification may assist the management of a snakebite victim. However, promoting the capture of the offending snake after snakebite should be discouraged, owing to many associated disadvantages.

This study shows that a variety of prehospital interventions are adopted by snakebite victims in Sri Lanka. Although desirable prehospital interventions are adopted by most of the victims, a considerable percentage had practiced dangerous interventions such as application of a tourniquet, which carries a high risk of well-recognized adverse consequences. ${ }^{16}$ Moreover, a large percentage of viperine bite victims also had practiced application of tourniquet. Interestingly, none of the patients in this study had used pressure immobilization. Therefore, we stress the need to educate the at-risk populations to avoid tourniquet use for snakebite as well as other harmful interventions such as incision and suction of the bite site, a practice that was fortunately uncommon among the snakebite victims in Anuradhapura. However, splinting, a desirable practice for decreasing the rate of venom absorption, had not been performed by any of the patients. Therefore, we emphasize the need of awareness programs to educate at-risk populations on the desirable first aid interventions in snakebite.

The indigenous treatments received by patients included medications applied over the bite site, nasal insufflations, oral liquid, and solid forms. Interestingly, little information exists in the Western medical literature about snakebite management in the native medicinal system in Sri Lanka ("Deshiya Chikithsa"). The native physicians classify the venomous snakes into 3 groups: "naga" (cobra), "mandala" (all viper species), and "rajala" (kraits and mildly venomous colubrids). According to the native therapeutic methods, the venoms of these 3 snake groups mainly harm different elements of the body: "vatha," "pith," and "sem," respectively. Type of treatment option used depends on the severity of the envenoming and the type of snake group involved. When the offending snake group cannot be verified, the native physicians use a method called "dutha lakshana," where the signs of the envenomed patient, characteristics of the persons who accompany the patient, and the direction from which they enter the physician's place are used in assuming what is the offending snake. Interestingly, many of these medications are not prepared ahead by the native treatment practitioners. Once a snakebite victim is brought to the local physician, the physician prepares medicines from freshly collected plant material. Different compositions of these herbs are ground to a paste and applied over the bitten site, used as oral decoctions, and nasal insufflations. Further, different oils prepared from these herbs are also used for local application over the bitten site. Commonly, tender leaves of fire plant (Plumbago indica), dwarf Ceylon Atalantia (Atalantia rotundifolia),
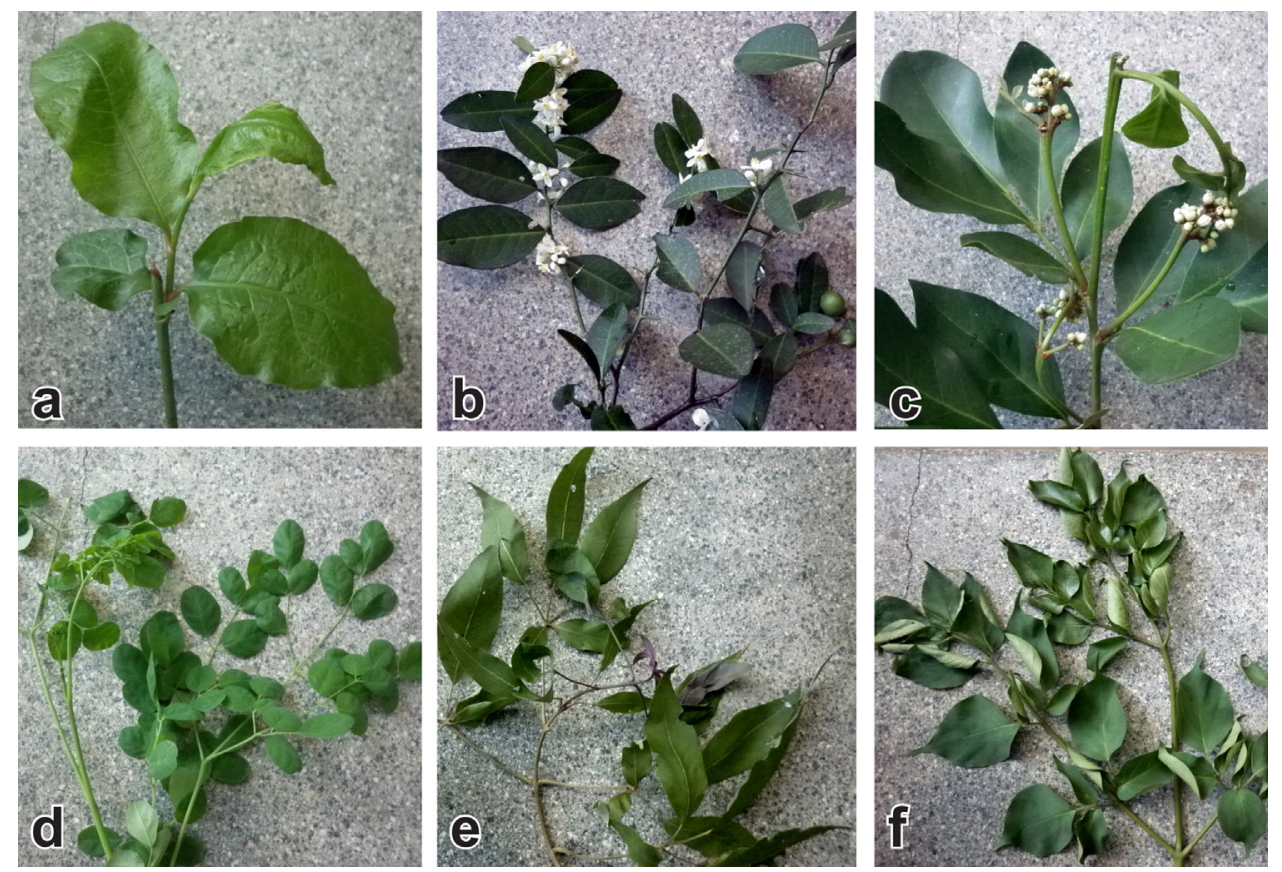

Figure 2. Leaves of the different plants used by the native medicine practitioners for snakebite treatment: (a) Plumbago indica; (b) Atalantia rotundifolia; (c) Glycosmis pentaphylla; (d) Moringa oleifera; (e) Litsea iteodaphne; and (f) Oroxylum indicum. 
orangeberry (Glycosmis pentaphylla), drumstick tree (Moringa oleifera), Kalu nika (Litsea iteodaphne), lime (Citrus aurantifolia), and the leaves and bark of broken bones tree (Oroxylum indicum) are used in the preparation of medications (Figure 2) (personal communication, Dr Lenawawidanarachchilage Dissanayake, native treatment practitioner).

Some of the information described in this paper was obtained from an informant in cases where the patient was unconscious or having altered consciousness due to severe envenoming. The subjectivity associated with this method may affect the data quality of this study. However, considering the importance of including the socio-epidemiological data of the severely envenomed patients, information from a third party was also included in such cases.

Unlike many communities in regions with high snakebite incidence (eg, South Asia), ${ }^{17}$ the utilization of indigenous/ayurvedic treatments as the initial intervention has been very rare among the snakebite victims studied here. Interestingly, according to the accessibility index and the poverty index, most of the areas in Anuradhapura district are rural and poor, compared to other districts in Sri Lanka. ${ }^{18}$ Therefore, this finding may be a reflection of public confidence in government healthcare facilities, their ready availability, and their accessibility. However, as these are hospital-based data, a considerable bias could be associated with generalizing the results to the entire community in Sri Lanka. Therefore, community-based data are required to further study the treatment-seeking behavior of snakebite victims in Sri Lanka.

\section{Conclusions}

This study shows that the typical snakebite patient in Anuradhapura is a male, middle-aged farmer, highlighting the burden of snakebite as an occupational health hazard in the area. However, the victims were from a range of occupations and age groups, highlighting the widespread burden of snakebite to the society. Those who seek native traditional or nonmedical treatment are very few among snakebite victims admitted to hospitals. Although many victims had recommended first aid interventions, a considerable proportion of snakebite victims in this area still use inappropriate first aid treatments after snakebite, indicating the persistence of these practices in Sri Lanka.

\section{Acknowledgments}

We wish to thank the medical and nursing staff of the emergency treatment unit and the medical units of THA. We are grateful to Dr Lenawawidanarachchilage
Dissanayake for sharing his knowledge on the native snakebite treatments with us.

Authors' contributions: SAMK conceived the idea; SAMK, SM, and RP supervised the study; IR and CW did data collection; KM, AS, and CR did identification of snakes and analysis of data; and SAMK and AS drafted the paper. All authors contributed to the final version of the manuscript and approved it. SAMK is the guarantor of the study.

\section{References}

1. Kasturiratne A, Wickremasinghe AR, de Silva N, et al. The global burden of snakebite: a literature analysis and modelling based on regional estimates of envenoming and deaths. PLoS Med. 2008;5:e218.

2. Williams D, Gutiérrez JM, Harrison R, et al. for the Global Snake Bite Initiative Working Group, International Society on Toxinology. The Global Snake Bite Initiative: an antidote for snake bite. Lancet. 2010;375:89-91.

3. Annual Health Bulletin. Ministry of Health, Sri Lanka; 2007.

4. Kasturiratne A, Pathmeswaran A, Fonseka MMD, Lalloo DG, Brooker S, de Silva HJ. Estimates of disease burden due to land-snake bite in Sri Lankan hospitals. Southeast Asian J Trop Med Public Health. 2005;36:733-740.

5. Kularatne SAM. Clinical profile of snake envenoming: a study in North Central Province of Sri Lanka. The 23rd Bibile Memorial Oration in 2001. Sri Lanka J Med. 2001;10:4-12.

6. Maduwage K, Isbister GK, Silva A, Bowatta S, Mendis S, Gawarammana I. Epidemiology and clinical effects of hump-nosed pit viper (Genus: Hypnale) envenoming in Sri Lanka. Toxicon. 2013;61:11-15.

7. Ariyaratnam CA, Thuraisingam V, Kularatne SAM, et al. Frequent and potentially fatal envenoming by hump-nosed pit vipers (Hypnale hypnale and H. nepa) in Sri Lanka: lack of effective antivenom. Trans R Soc Trop Med Hyg. 2008;102:1120-1126.

8. Kularatne SA. Common krait (Bungarus caeruleus) bite in Anuradhapura, Sri Lanka: a prospective clinical study, 1996-98. Postgrad Med J. 2002;78:276-280.

9. Kularatne SA. Epidemiology and clinical picture of the Russell's viper (Daboia russelii russelii) bite in Anuradhapura, Sri Lanka: a prospective study of 336 patients. Southeast Asian J Trop Med Public Health. 2003;34: 855-862.

10. Kularatne SA, Budagoda BD, Gawarammana IB, Kularatne WK. Epidemiology, clinical profile and management issues of cobra (Naja naja) bites in Sri Lanka: first authenticated case series. Trans R Soc Trop Med Hyg. 2009;103:924-930.

11. De Silva PHDH. Snake Fauna of Sri Lanka With Special Reference to Skull, Dentition and Venom in Snakes. Colombo: National Museums of Sri Lanka; 1980. 
12. Maduwage K, Silva A, Manamendra-Arachchi K, Pethiyagoda R. A taxonomic revision of the South Asian pit viper genus Hypnale (Fitzinger). Zootaxa. 2009;2232:1-28.

13. Cruz LS, Vargas R, Lopes AA. Snakebite envenomation and death in the developing world. Ethn Dis. 2009;19: 42-46.

14. Warrell DA. Snake bite. Lancet. 2010;375:77-88.

15. Tun-Pe Aye-Aye-Myint, Khin-Aye-Kyu, Maung-Maung-Toe. Acceptability Study of Protective Boots Among Farmers of
Taungdwingyi Township. Management of Snakebite and Research. New Delhi: World Health Organization; 2002:7-11.

16. Warrell DA. Guidelines for the Management of SnakeBites. India, World Health Organization; 2010.

17. Alirol E, Sharma SK, Bawaskar HS, Kuch U, Chappuis F. Snake bite in South Asia: a review. PLoS Negl Trop Dis. 2010;4:e603.

18. Poverty Indicators. Department of Census and Statistics, Sri Lanka; 2009. 